Special issue of the 2nd International Conference on Computational and Experimental Science and Engineering (ICCESEN 2015)

\title{
Micropropagation of Walnut (Juglans regia L.)
}

\author{
K. KePENEK ${ }^{a, *}$ AND Z. KOLAĞASI ${ }^{b}$
}

${ }^{a}$ Süleyman Demirel University Faculty of Agriculture, Agricultural Biotechnology Department, Isparta 32260, Turkey ${ }^{b}$ Süleyman Demirel University, Faculty of Agriculture, Horticultural Department, Isparta 32260, Turkey

The objective of this work was to establish regeneration protocol for walnut (Juglans regia L.) by multiplication of shoots from axillary buds. Different concentrations of TDZ $(0.0,1.0,2.5,5.0 \mathrm{mg} / \mathrm{l}), \mathrm{IBA}(0.0,1.0,2.5,5.0 \mathrm{mg} / \mathrm{l})$ or IBA together with TDZ were investigated to optimize regeneration for the multiplication in the NGE (Sanchez) culture medium. Multiplication rate increased with increased concentration of TDZ or IBA together with TDZ. The highest mean multiplication rate was observed in the fourth subculture with $2.5 \mathrm{mg} / \mathrm{l} \mathrm{TDZ}+2.5 \mathrm{mg} / 1 \mathrm{IBA}$ reaching 5.33 shoots per explant. The shoots supplemented with $5 \mathrm{mg} / \mathrm{l}$ IBA $(62.71 \%)$ had higher number of rooted shoots than those supplemented with $2.5 \mathrm{mg} / \mathrm{l}$ IBA $(45.66 \%)$. With $73.24 \%$ of rooting, the shoots rooted on medium containing $2.5 \mathrm{mg} / \mathrm{l}$ IBA after etiolation application had higher number of rooted shoots than those supplemented with $5 \mathrm{mg} / \mathrm{IBA}$ with $64.69 \%$ of rooting after etiolation application. The highest mean survival rate of the shoots was observed in $2.5 \mathrm{mg} / 1 \mathrm{TDZ}+2.5 \mathrm{mg} / \mathrm{l} \mathrm{IBA}$ reaching $35.27 \%$. Results showed that walnut in vitro micropropagation is feasible and the best growth percentage was obtained in $5.0 \mathrm{mg} / \mathrm{TDZ}$, and $2.5 \mathrm{mg} / \mathrm{l} \mathrm{TDZ}$ with $2.5 \mathrm{mg} / 1 \mathrm{IBA}$.

DOI: $10.12693 /$ APhysPolA.130.150

PACS/topics: 87.17.Uv, 87.80.Rb

\section{Introduction}

Walnut (Juglans regia L.) is a native tree of the forest of Turkey. Its wood is of excellent quality and widely appreciated. It is exported for the confection of luxury furniture and as timber for constructions and carpentry. It is a rich source of minerals, protein, and fat and has concentrated source of energy. The seeds are recalcitrant and it has strong integument dormancy and their germination is irregular, making its natural propagation difficult [1]. Low percentage of seed germination and long propagation cycle are the main constraints on the development of high yielding cultivars through hybridization [2]. Moreover, the rooting rate of cuttings is low $[3,4]$, thus limiting its vegetative propagation for replanting. Low percentage of seed germination and long propagation cycle are the main problems of propagation $[5,6]$.

Woody plants are still often very difficult to propagate in many different types of media which have been employed. One of the new and important ways of plant propagation is micropropagation or tissue culture technique [7-10]. Using this technique is preferred due to its high propagation of plants in short periods, especially for low production of vegetative propagation, or for difficult to regenerate species in natural conditions, as in the case of walnut. Considering these difficulties, micropropagation represents an important tool for walnut propagation. In vitro cultures of Juglans sp. L. can be established starting from micro-shoots or zygotic embryos from adult plants $[2,4,11]$. The medium is the most important aspect of in vitro micropropagation protocol for plant mass production and proliferation. This

\footnotetext{
* corresponding author; e-mail: kahramankepenek@sdu.edu.tr
}

technique may be successfully used for mass propagation of selected genotypes of walnut, conservation and genetic improvement $[12,13]$.

The production of plants from axillary buds or shoots has proved to be the most generally applicable and reliable method of in vitro propagation [14, 15]. Micropropagation culture, in which explants (axillary buds or shoots) are excised aseptically and cultured on the medium, and enables faster multiplication of plants. In addition, also reduces the generation cycle in woody plants like walnut where seeds require stratification period of 2-3 months for propagation [4, 16-19]. The most important problems of walnut micropropagation are sensitivity to oxidation of phenolic component in explants, pollution inside explants, adapting to culture medium, rooting and difficulties related to the transfer to soil. Sensitivity to oxidation of phenolic component in explants, pollution inside explants, adapting to culture medium, rooting and difficulties related to the transfer to soil are the most important problems of walnut micropropagation.

Different media have been used for the proliferation stage of the explants. There are few studies about micropropagation of species from Juglandaceae family and none of them are related to walnut. For micropropagation of Juglans sp. different culture media have been used, such as Driver and Kuniyuki (DKW) [20], Lloyd and McCown (WPM) [21], Murashige and Skoog (MS) [22], and the medium developed by Sanchez (NGE) [23] with varying success [19]. Revilla et al. [24] reported that the best growth was using a primary culture in half strength Knop's medium and a second one in Miller medium with $1 \mathrm{mg} / \mathrm{l}$ benzylaminopurine (BAP) and $0.1 \mathrm{mg} / \mathrm{l}$ indole-3-butyric acid (IBA) [24]. In micropropagation studies of $J$. regia L. [25] there were used the culture medium $\mathrm{K}(\mathrm{h})$ with different $\operatorname{BAP}(0,4,20$ 
and $40 \mathrm{mM})$ and IBA $(0,0.4,4$ and $20 \mathrm{mM})$ concentrations $[19,25]$. The best treatment was $40 \mathrm{mM}$ BAP without IBA, resulting in a germination percentage of $80 \%$. In another study [26], different culture media and different BAP concentrations were compared and it was seen that that the most appropriate medium was MS.

Some authors analyzed the factors which affect multiplication, comparing culture media, gelling agents and growth regulators. Saadat and Hennerty obtained higher shoot proliferation both in MS media plus phytagel $(2.2 \mathrm{~g} / \mathrm{l})$ and DKW media plus phytagel (2.7 new shoot per explant) [27]. The best proliferation results were obtained with $1 \mathrm{mg} / \mathrm{l}$ of BAP plus $0.01 \mathrm{mg} / \mathrm{l}$ of IBA.

The root induction under dark conditions in the presence of auxins in the culture media permits to obtain up to $83 \%$ root formation. Sánchez-Olate [28] indicated that the best rhizogenic response came from apical shoot segments $2 \mathrm{~cm}$ long, showing a close relationship between auxin concentration and exposure time. Rooting rate of $85 \%$ was achieved inducing microshoots in MS media with major nutrients diluted to $25 \%$ and in complete darkness. The induction time depends on the applied auxin concentration. For a concentration of $3 \mathrm{mg} / \mathrm{l}$ the induction phase should last 7 days while for a concentration of $5 \mathrm{mg} / \mathrm{l}$ the induction phase should be 3 days [28]. However, there are differences in rooting rates depending on the cultivar used [29].

In view of all these references, it is necessary to determine the optimal in vitro conditions for particular plant material, determining the optimum media for in vitro micropropagation and the growth regulator concentration for the proliferation stage of the obtained explants. It is important for walnut species of the Juglandaceae family, to carry experiments to establish micropropagation protocols of regeneration, because of the economic and ecological importance of walnut species for plant mass production and proliferation.

In this study the effects of TDZ/IBA ratio on the survival rate, organogenesis (regeneration), callus induction and multiplication (axillary shoots proliferation), the rooting rate, the number of roots, the root length, the root number, the nodium length from shoot tips of Juglans regia L. genotypes for the in vitro micropropagation protocol for plant mass production and proliferation of walnut were investigated on NGE basal media.

\section{Materials and methods}

Initial material for in vitro vegetative multiplication was obtained from newly growing shoots of walnut cultivars (J. regia L.) of Chandler, Kaplan-86 (Kaplan) and Yalova-1 $(Y-1)$ collected in early May. Walnut cultivars grafted on seedling of $J$. regia were maintained in the greenhouse conditions with biweekly applications of a fungicide mixture of Streptomycine-Mancozeb and Benlate in order to reduce contamination levels. The walnut trees were grown in the greenhouse conditions during the spring season. Apical glabrous shoot tips and leaf buds were collected from vegetative shoots two-four weeks for explants. Shoot tips and leaf buds (young herbaceous shoot - semilignified shoot), had active vegetative leaf buds (approximately $0.5-0.8 \mathrm{~cm}$ diameter, $3-$ $5 \mathrm{~cm}$ in length internodes and the presence of vegetative leaf buds). Subsequently, they were cut in laminar flow chamber keeping vegetative shoots and were washed in the solution of Kasugamycin hydrochloride hydrate (bactericide) $(500 \mathrm{mg} / \mathrm{l})$ and Captan $(3 \mathrm{~g} / \mathrm{l})$; and were left in a bottle under sterile conditions in water and were sealed with plastic bags. These vegetative leaf buds and shoot tips were transferred to the lab and then were washed with tap water for $30 \mathrm{~min}$ and then were transferred to an antioxidant aqueous solution [polyvinylpyrrolidone (PVP) $(500 \mathrm{mg} / \mathrm{l})$, cysteine $(20 \mathrm{mg} / \mathrm{l})$ and ascorbic acid (AA) $(5 \mathrm{mg} / \mathrm{l})]$ and a fungicide solution [(Captan $(1 \mathrm{~g} / \mathrm{l})$ and Benomyl $(1 \mathrm{~g} / \mathrm{l})]$. Shoots tips and leaf buds were disinfected into continuous stirring by immersion in $70 \%$ $(\mathrm{v} / \mathrm{v})$ ethanol/water solution for a few min followed by $20 \%$ sodium hypochlorite fresh solution with two drops of Tween 20 per $100 \mathrm{ml}$ for $20 \mathrm{~min}$, followed by four times rinsed in sterile deionized water continuous stirring for $15 \mathrm{~min}$. Then shoot tips were soaked into an antioxidant aqueous solution of PVP $(500 \mathrm{mg} / \mathrm{l})$ and AA $(150 \mathrm{mg} / \mathrm{l})$ or L-cysteine $(50 \mathrm{mg} / \mathrm{l})$ for $2 \mathrm{~h}$ before culture until transferred to culture media in test tubes. Then these shoot tips were dried on sterile filter paper before they were cultivated in culture media in test tubes in a laminar flow chamber. Apical glabrous shoot tips were placed into the culture boxes of Kepenek (aeration system, plexiglass, $6000 \mathrm{ml}$ ) [30] containing a medium composed of $1 / 2$ diluted MS [22] vitamins, diluted $\frac{1}{4}$ of NGE salts [23], PVP (500 mg/l), glucose (40 g/l), rockwool and vermiculite $(2500 \mathrm{ml}$ medium $/ 3500 \mathrm{ml}$ vermiculite) with different concentration Thidiazuron $\left(N\right.$-phenyl- $N^{\prime}$ 1,2,3-thidiazol-5-ylurea) (TDZ) $(0.0,1.0,2.5$, or $5.0 \mathrm{mg} / \mathrm{l})$ or indole-3-butyric acid (IBA) $(0.0,1.0,2.5$, or $5.0 \mathrm{mg} / \mathrm{l})$, $\mathrm{pH}=6$.

Then culture boxes (Fig. 1) were left in a dark cultivation chamber during 10 days for etiolation treatment. The cultures were maintained six weeks at the same conditions. The percentage of etiolation of the shoots was evaluated after etiolation was used. Each treatment consisted of three replicates $(n=30)$. In order to calculate the mean multiplication rate (etiolation + TDZ) and rooting rate (etiolation + IBA), the nodium length, following the etiolation treatment the top of shoot tips (approximately $1.5-2.5 \mathrm{~cm}$ long) were cut and placed on a medium composed of the NGE basal medium supplemented PVP (500 mg/l), glucose $(40 \mathrm{~g} / \mathrm{l})$ and solidified with a gelrite (Phytagel) $(3.0 \mathrm{~g} / \mathrm{l})$ with different concentration alone of TDZ $(0.0,1.0,2.5$, or $5.0 \mathrm{mg} / \mathrm{l})$, IBA $(0.0$, $1.0,2.5$, or $5.0 \mathrm{mg} / \mathrm{l})$ or IBA together with TDZ. Then all were added an aqueous solution containing with $2 \mathrm{~g} / \mathrm{l}$ of DIECA (diethyl carbamate acid, tri-hydrated sodium salts) in a culture tube (one single bud per tube) in laminar flow chamber. The culture tubes were used for establishment of in vitro (during initiation, multiplication 
and root induction phases) having $2.5 \mathrm{~cm}$ in diameter and $15 \mathrm{~cm}$ in height containing $15 \mathrm{ml}$ of liquid NGE medium each and were closed with polypropylene caps. The culture tubes of keeping shoots were transferred for six weeks in cultivation chamber during light/dark photoperiod of 16 and $8 \mathrm{~h}$ photoperiod light intensity $\left(75 \mu \mathrm{mol} \mathrm{m}{ }^{-2} \mathrm{~s}^{-1}\right)(75 \%$ red $+10 \%$ blue $+15 \%$ green $)$ of under LED light at $26 \pm 1^{\circ} \mathrm{C}$ until vegetative leaf bud shooting. The cultures were maintained six weeks at the same conditions. Shoots tips $(0.5$ to $2.5 \mathrm{~cm} \mathrm{long})$ originating from the subculture of the multiplication phase were used.

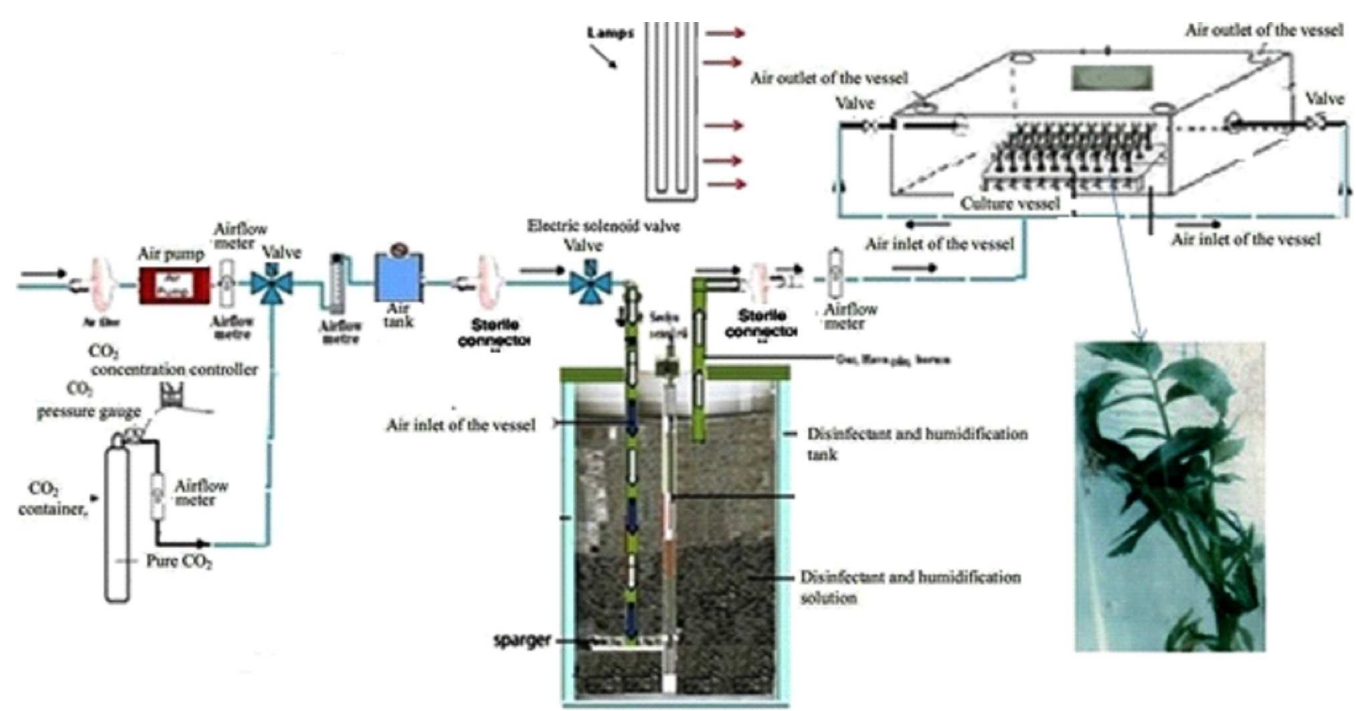

Fig. 1. Culture vessel for rooting of microshoots of walnut. Polypropylene box with bunches of shoots inserted in perforated platform with their cut ends touching the medium.

Prior to sterilization, $\mathrm{pH}$ of the culture media was adjusted to 6.0. After adjusting the $\mathrm{pH}$, phytagel was added to the media and it was heated until all compounds were completely dissolved. PVP was added to medium before autoclaving, but AA was added to medium after autoclaving by filtration sterilization. After adjusting the $\mathrm{pH}$ to 5.8 with $0.1 \mathrm{~N} \mathrm{KOH}$ or $0.1 \mathrm{~N} \mathrm{HCl}$, the media were autoclaved at $121^{\circ} \mathrm{C}$, at a pressure of $105 \mathrm{kPa}$ for $20 \mathrm{~min}$.

The caps of the tubes were gradually opened and the rooted plants preacclimatized in the growth room for 7 days. After they were subsequently removed from the tubes they were planted into plastic caps $\left(70 \mathrm{~cm}^{3}\right)$ containing the following mixtures: "Klasman peat : agroperlite $(1: 1)+$ fertilization". They were maintained under intermittent mist (1 $\mathrm{min}$ every $5 \mathrm{~min}$ ) in a greenhouse with a temperature of $24 \pm 2{ }^{\circ} \mathrm{C}$ and $\mathrm{RH}$ of $85 \pm 5 \%$. The percentage of the plant survival was recorded after 4 weeks. After acclimatization, the rooted plants were treated with Promalin (19 g/1 BA + $19 \mathrm{~g} / \mathrm{l}$ gibberellin A4-A7) growth regulator.

The experiment was performed as a factorial experiment design. These factors were Chandler, Kaplan and Yalova-1 $(Y-15)$ cultivars $(J$ regia L.), and different TDZ and IBA concentrations; etiolation + TDZ, etiolation + IBA and cultivar during 4 serial subcultured. The treatments were arranged in a completely randomized design with three replications $(n=30)$, with each replication containing 10 apical glabrous shoots tips. During six weeks the recorded data in four subcultures were: the average number of the multiplication rate, the regeneration rate, the callus index, the rooting rate, the number of roots, the root length, the root number, the nodium length per explant and the mean of the shoot lengths of axillary shoots. The new axillary shoots were individualized and subcultured every six weeks. The mean multiplication rate was calculated by counting the axillary shoots originating in each subculture. The percentage survival rate of the shoot tips was evaluated after six weeks. The effect of etiolation alone or TDZ or IBA on the elongation of the shoots (the nodium length) were studied. Three replicates of tubes were with one shoot per tube $(n=30)$. After six weeks, the percentage of rooted shoots, the mean number of roots per shoot and mean length of roots were calculated. All statistical analyses were performed using GLM on SAS [31]. The data were submitted to an analysis of variance analysis (ANOVA) to calculate statistical significance, and the mean \pm SE (standard error). Significance level was determined by means comparison using Tukey-Kramer multiple test at $p<0.05$ level.

\section{Results and discussion}

The explants presented a high percentage of survival and $4.4 \%$ of fungal contamination. Significant differences were found among cultivars in terms of the survival rates among walnut explants. Regardless of treatments, the 
survival rates of explants ranged from $35.27 \%$ to $23.79 \%$. The highest overall survival rate among cultivars was obtained from Kaplan cultivar. Overall, IBA 2.5 + TDZ 2.5 combination provided the highest survival rate $(35.27 \%)$ among the treatments. Among the cultivars, the highest survival rate $(38.41 \%)$ was also obtained with IBA $2.5+$ TDZ 2.5 combination in the cultivar $Y-1$. The use of TDZ 2.5 alone was determined to be suitable for the micropropagation of walnut in terms of the survival rates of explants.

The plant growth regulators doses used in the study were also effective on the survival rate. In terms of survival rate, the use of IBA $2.5+$ TDZ 2.5 combination was more effective by comparison with the use of TDZ 2.5 alone. The lowest survival rate was obtained from the control (Table I).

TABLE I

Effect of different TDZ and IBA concentrations on NGE medium on in vitro survival rate, regeneration and callus index from shoot tips of walnut cultivars. $Y-1$ - Yalova-1 cultivar.

\begin{tabular}{|c|c|c|c|c|c|c|c|c|c|c|c|c|}
\hline \multirow[b]{2}{*}{ Treatment $[\mathrm{mg} / \mathrm{l}]$} & \multicolumn{4}{|c|}{ Survival rate $^{a}[\%]$} & \multicolumn{4}{|c|}{ Regeneration $^{b}[\%]$} & \multicolumn{4}{|c|}{ Callus index ${ }^{c}$} \\
\hline & Chandler & Kaplan & $Y-1$ & A & Chandler & Kaplan & $Y-1$ & B & Chandler & Kaplan & $Y-1$ & $\mathrm{C}$ \\
\hline 0.0 & $23.36^{h}$ & $25.65^{f g}$ & $22.36^{h i}$ & 23.79 & 6.54 & 5.19 & 7.34 & 6.35 & 1.06 & 1.14 & 1.08 & 1.09 \\
\hline TDZ 1.0 & $25.14^{g}$ & $30.43^{d e}$ & $21.98^{i}$ & 25.85 & $13.56^{i}$ & 13.06 & $14.27^{i}$ & 13.63 & $2.68^{g}$ & $2.73^{g}$ & $2.40^{h}$ & 2.60 \\
\hline TDZ 2.5 & $27.37^{f}$ & $32.28^{c d}$ & $24.11^{g h}$ & 27.92 & $19.91^{d}$ & $18.03^{e f}$ & $19.14^{d e}$ & 19.02 & 2.24 & 2.25 & 2.04 & 2.17 \\
\hline TDZ 5.0 & $28.49^{e f}$ & $35.71^{a b}$ & $25.45^{g}$ & 29.88 & $19.31^{d e}$ & $18.59^{e}$ & $20.17^{d}$ & 19.35 & $3.46^{d}$ & $3.55^{c}$ & $3.28^{d e}$ & 3.43 \\
\hline IBA $1.0+$ TDZ 1.0 & $27.55^{f}$ & $34.59^{b}$ & $29.18^{e}$ & 30.44 & $14.61^{\imath}$ & 13.17 & $18.20^{e f}$ & 15.32 & $2.86^{f g}$ & $3.10^{e}$ & $2.76^{g}$ & 2.90 \\
\hline IBA $2.5+$ TDZ 2.5 & $31.14^{d}$ & $36.26^{a b}$ & $38.41^{a}$ & 35.27 & $21.84^{c}$ & $19.71^{d e}$ & $20.29^{d}$ & 20.61 & $2.85^{f g}$ & $2.85^{g h}$ & $2.91^{f}$ & 2.87 \\
\hline IBA $5.0+$ TDZ 5.0 & $29.49^{e}$ & $37.36^{a}$ & $33.26^{b c}$ & 33.37 & $23.04^{b}$ & $19.18^{\text {de }}$ & $24.35^{a}$ & 22.19 & $4.05^{a}$ & $4.12^{a}$ & $4.09^{a}$ & 4.08 \\
\hline overall mean & 23.62 & 33.18 & 27.82 & - & 16.97 & 15.27 & 17.68 & - & 2.74 & 2.82 & 2.65 & \\
\hline
\end{tabular}

${ }^{a} n=30$ shoots explant means with different letters are significantly different at $P<0.05$.

${ }^{b} n=30$ explant means. \% regeneration means with different letters are significantly different at $P<0.05$.

${ }^{c}$ Callus index ranged from 0 (no callus) to 5 (81 to $100 \%$ callus on the shoots). Callus index mean values with different letters between cultivars denote significant differences at $P<0.05$. According to Tukey-Kramer multiple comparison test at $P<0.05$. Data are expressed as mean value \pm s.d.

A: overall mean on survival rate at hormon concentration, B: overall mean on regeneration at hormon concentration,

$\mathrm{C}$ : overall mean on callus index at hormon concentration.

TABLE II

Influence of different TDZ and IBA concentrations on multiplication rate $(M R)$ (axillary shoots per explant) and length shoots $[\mathrm{cm}](L S)$ from shoot tips of during four serial subcultures on NGE medium.

\begin{tabular}{|c|c|c|c|c|c|c|c|c|c|c|}
\hline \multirow{3}{*}{ Treatment $[\mathrm{mg} / \mathrm{l}]$} & \multicolumn{10}{|c|}{ Subculture cycles } \\
\hline & \multicolumn{2}{|c|}{ Subculture 1} & \multicolumn{2}{|c|}{ Subculture 2} & \multicolumn{2}{|c|}{ Subculture 3} & \multicolumn{2}{|c|}{ Subculture 4} & \multirow[t]{2}{*}{ A } & \multirow[t]{2}{*}{ B } \\
\hline & $M R$ & $L S$ & $M R$ & $L S$ & $M R$ & $L S$ & $M R$ & $L S$ & & \\
\hline 0 (control) & $1.22 \pm 0.3$ & $3.55^{a b} \pm 0.4$ & $1.64 \pm 0.2$ & $3.34^{c} \pm 0.5$ & $1.76 \pm 0.3$ & $3.40^{a} \pm 0.5$ & $1.96 \pm 0.2$ & $3.12^{c} \pm 0.4$ & 1.64 & 3.35 \\
\hline TDZ 1.0 & $2.59 \pm 0.2$ & $2.86^{f} \pm 0.3$ & $2.68 \pm 0.3$ & $2.57^{g} \pm 0.4$ & $2.71 \pm 0.2$ & $2.38^{g} \pm 0.3$ & $3.19^{h i} \pm 0.1$ & $2.20^{h} \pm 0.3$ & 2.79 & 2.50 \\
\hline TDZ 2.5 & $3.40^{g h} \pm 0.2$ & $2.73^{f} \pm 0.2$ & $3.68^{e f} \pm 0.2$ & $2.78^{f} \pm 0.4$ & $3.75^{f} \pm 0.1$ & $2.59^{f} \pm 0.2$ & $3.69^{f g} \pm 0.2$ & $2.54^{f} \pm 0.3$ & 3.63 & 2.66 \\
\hline TDZ 5.0 & $3.54^{g} \pm 0.3$ & $2.55^{g} \pm 0.5$ & $3.93^{e} \pm 0.1$ & $2.44^{h} \pm 0.3$ & $4.09^{e} \pm 0.3$ & $2.42^{g} \pm 0.4$ & $3.77^{f} \pm 0.3$ & $2.47^{g} \pm 0.3$ & 3.83 & 2.47 \\
\hline TDZ $1.0+$ IBA1.0 & $4.38^{d} \pm 0.1$ & $3.88^{a} \pm 0.3$ & $4.71^{a b} \pm 0.1$ & $3.53^{b} \pm 0.3$ & $4.18^{e} \pm 0.2$ & $3.36^{a} \pm 0.3$ & $4.48^{d} \pm 0.2$ & $3.22^{c} \pm 0.5$ & 4.43 & 3.49 \\
\hline TDZ $2.5+$ IBA2.5 & $4.75^{b} \pm 0.3$ & $3.71^{a} \pm 0.4$ & $4.87^{a} \pm 0.3$ & $3.79^{a} \pm 0.2$ & $5.12^{a} \pm 0.1$ & $3.53^{a} \pm 0.5$ & $5.33^{a} \pm 0.2$ & $3.58^{a} \pm 0.4$ & 5.01 & 3.65 \\
\hline TDZ $5.0+$ IBA5.0 & $5.32^{a} \pm 0.2$ & $3.72^{a} \pm 0.3$ & $5.02^{a} \pm 0.4$ & $3.53^{b} \pm 0.5$ & $5.30^{a} \pm 0.3$ & $3.48^{a} \pm 0.4$ & $4.84^{b} \pm 0.3$ & $3.42^{a} \pm 0.6$ & 5.12 & 3.53 \\
\hline Overall mean & 3.60 & 3.28 & 3.79 & 3.14 & 3.84 & 3.02 & 3.89 & 2.93 & - & - \\
\hline
\end{tabular}

Shoots per explant mean values with different letters between cultivars denote significant differences according to TukeyKramer multiple comparison test at $P<0.05$. Data are expressed as mean value \pm s.d.

A: Overall mean on multiplication rate at hormone concentration, B: Overall mean on length shoots at hormon concentration.

Hormone treatments were also effective on the regeneration rates. Significant differences were observed among walnut cultivars in terms of their regeneration rates. $Y-1$ cultivar has shown higher regeneration rate by comparison with the other two cultivars (Table I). In vitro shoot regeneration of walnut is highly genotype dependent.

While the highest regeneration rate $(22.19 \%)$ was obtained from IBA $5.0+$ TDZ 5.0 combination and TDZ
5.0 treatments $(19.35 \%)$, the lowest rate was observed from the control treatment $(6.35 \%$, Table I).

The callus index has shown significant differences among walnut cultivars. The Kaplan cultivar had the highest callus index among the cultivars. The hormone doses used also had significant effects on callus index. The highest callus index (4.08) was obtained from the IBA $5.0+$ TDZ 5.0 combination. The callus index increased with the increases in TDZ and IBA doses either 
alone or in combination. Either since a high callus index is not desirable in the micropropagation of walnut, TDZ 2.5 treatment or IBA $2.5+$ TDZ 2.5 combination has been found to be suitable for the micropropagation of walnut (Table I). In $Y-1$ walnut cultivar significant differences were observed among treatments in terms of the multiplication rate in the number of subculture treatments for micropropagation. The multiplication rate increased with the increases in the number of subcultures. For instance, the multiplication rate was 3.6 in the first subculture and it increased to 3.89 in the fourth subculture (Table II). Saadat and Hennerty [27] support these results.

In terms of the number of subcultures, TDZ or IBA doses either alone or in combinations were effective on the micropropagation rate. While the highest micropropagation rate was obtained from IBA 5.0 + TDZ 5.0 combination, the lowest rate was observed in the control. The data suggest that both TDZ 2.5 treatment and IBA $2.5+$ TDZ 2.5 combination is suitable for the micropropagation of walnut (Table II).

In the micropropagation study with $Y-1$ cultivar, significant differences were observed among TDZ or IBA doses in terms of the shoot lengths in the subcultures. In general, as the number of subcultures increased, shoot lengths decreased (Table II). After the third subculture period there was an effect on the incidence of apical necrosis microshoots.
In all subcultures TDZ and IBA doses alone or in combination affected shoot length. Generally, as the number of subcultures, TDZ and IBA doses increased, shoot length decreased. The highest shoot length was obtained from TDZ $1.0+$ IBA 1.0 treatment in the first subculture. The results suggest that in terms of shoot length TDZ 2.5 and IBA $2.5+$ TDZ 2.5 treatments can be used for the micropropagation of walnut (Table II).

The effects of IBA doses on the rooting rate, the number of roots and root length were varied with cultivars (Table III). The rooting rate increased with increases in IBA doses. The highest rooting rate $(62.71 \%)$ was 5.0 IBA dose, but the rooting rate in the control treatment was $14.41 \%$. The results suggest that 5.0 IBA dose alone is suitable for the micropropagation of walnut in terms of rooting rate (Table III). In walnut, IBA doses affected the number of roots significantly. Significant differences were observed between cultivars and IBA doses in terms of the number of roots. The highest number of roots was observed in the cultivar Chandler (Table III). Rooting rates were achieved inducing microshoots in NGE media within complete darkness. Sánchez-Olate [28] and Ríos Leal et al. [32] supported these results.

In walnut, cultivars and IBA doses have shown differences in terms of the root length. IBA doses used significantly affected root length. The $Y-1$ cultivar had significantly higher root length than the other cultivars (Table III).

TABLE III

The influence different IBA concentrations on rooting rate, number of roots and length of the roots from shoot tips of walnut cultivars on NGE medium.

\begin{tabular}{|c|c|c|c|c|c|c|c|c|c|c|c|c|}
\hline \multirow[b]{2}{*}{$\mathrm{BA}[\mathrm{mg} / \mathrm{l}]$} & \multicolumn{4}{|c|}{ Rooting rate [\%] } & \multicolumn{4}{|c|}{ Number of the roots } & \multicolumn{4}{|c|}{ Length of the roots $[\mathrm{cm}]$} \\
\hline & Cha & Kaplan & $Y-1$ & A & Chandler & Kaplan & $Y-1$ & $\mathrm{~B}$ & Chandler & Kaplan & $Y-1$ & $\mathrm{C}$ \\
\hline 0.0 & 15.1 & 13.4 & $14.62 \pm 1.2$ & 14.41 & 2. $56^{i} \pm 0.27$ & 2.31 & $2.24 \pm 0.25$ & 2.37 & $2.82 \pm 0.31$ & $2.71 \pm 0.20$ & $2.75 \pm 0.27$ & 2.76 \\
\hline 1.0 & $37.28^{1} \pm 1.3$ & $34.28 \pm 1.1$ & $41.12^{h} \pm 1.1$ & 37.56 & $4.16^{a b} \pm 0.25$ & $3.45^{d} \pm 0.18$ & $4.31^{a} \pm 0.24$ & 3.97 & $2.98 \pm 0.23$ & $2.89 \pm 0.14$ & $2.92 \pm 0.38$ & 2.93 \\
\hline 5.0 & $62.37^{b} \pm 1.0$ & $59.03^{c} \pm 0.9$ & $66.74^{a} \pm 1.3$ & 62.71 & $3.89^{b} \pm 0.21$ & $3.66^{c d} \pm 0.31$ & $3.92^{b} \pm 0.12$ & 3.82 & $3.18 \pm 0.22$ & $3.06 \pm 0.32$ & $3.23 \pm 0.18$ & 3.15 \\
\hline overall mean & 39.5 & 38.03 & 42.72 & - & 3.65 & 3.29 & 3.50 & - & 3.03 & 2.98 & 3.04 & - \\
\hline
\end{tabular}

Mean values within vertical colunns different letters between IBA concentrations denote significant differences according to Tukey-Kramer multiple comparison test at $P<0.05$. Data expressed as mean value \pm s.d..

A: Overall mean on rooting rate at IBA doses, B: Overall mean on number of the root at IBA doses, C: Overall mean on length of the root at IBA doses.

TABLE IV

The influence different TDZ and IBA concentrations in NGE medium on multiplication rate and rooting rate from shoot tips of walnut cultivars after dark for etiolation treatment.

\begin{tabular}{|c|c|c|c|c|c|c|c|c|c|c|}
\hline \multirow[b]{3}{*}{ Cultivars } & \multicolumn{5}{|c|}{ Multiplication Rate } & \multicolumn{5}{|c|}{ Rooting rate [\%] } \\
\hline & \multicolumn{4}{|c|}{ Etiolation + TDZ $[\mathrm{mg} / \mathrm{l}]$} & \multirow[b]{2}{*}{$\mathrm{A}$} & \multicolumn{4}{|c|}{ Etiolation + IBA $[\mathrm{mg} / \mathrm{l}]$} & \multirow[b]{2}{*}{ B } \\
\hline & 0.0 & 1.0 & 2.5 & 5.0 & & 0.0 & 1.0 & 2.5 & 5.0 & \\
\hline Chandler & $1.63 \pm 0.2$ & $3.93^{h} \pm 0.2$ & $5.41^{a} \pm 0.1$ & $4.97^{d} \pm 0.5$ & 3.98 & $19.06 \pm 1.2$ & $59.19^{d e} \pm 1.4$ & $75.37^{a} \pm 1.1$ & $67.12^{c} \pm 1.1$ & 55.18 \\
\hline Kaplan & $1.45 \pm 0.2$ & $3.35 \pm 0.1$ & $4.66^{f} \pm 0.3$ & $4.45^{h} \pm 0.3$ & 3.47 & $18.17 \pm 1.3$ & $48.27^{h} \pm 1.1$ & $69.81^{c} \pm 1.4$ & $61.25^{d} \pm 1.3$ & 49.37 \\
\hline$Y-1$ & $1.22 \pm 0.3$ & $3.59 \pm 0.1$ & $5.40^{c d} \pm 0.2$ & $5.54^{a} \pm 0.1$ & 3.93 & $19.28 \pm 1.1$ & $61.44^{d} \pm 1.2$ & $74.56^{a b} \pm 1.3$ & $65.71^{c d} \pm 1.2$ & 55.24 \\
\hline overall mean & 1.43 & 3.62 & 5.15 & 4.98 & & 18.83 & 56.30 & 73.24 & 64.69 & - \\
\hline
\end{tabular}

Evaluated 10 days-treatment etiolation after culture. Shoots per explant mean values with different letters between cultivars denote significant differences according to Tukey-Kramer multiple comparison test at $P<0.05$. Data are expressed as mean value \pm s.d.

A: Overall mean on multiplication rate at cultivar, B: Overall mean on rooting rate at cultivar. 
TABLE V

The influence after dark for etiolation treatment with different TDZ and IBA concentrations in NGE medium on mean nodium length from shoot tips of walnut cultivars.

\begin{tabular}{c|c|c|c|c|c|c|c|c|c}
\hline \hline & \multicolumn{9}{|c|}{ Nodium length $[\mathrm{cm}]$} \\
\cline { 2 - 7 } & \multicolumn{3}{|c|}{ Etiolation + IBA $[\mathrm{mg} / \mathrm{l}]$} & \multicolumn{3}{c}{ Etiolation + TDZ $[\mathrm{mg} / \mathrm{l}]$} & \\
\cline { 2 - 7 } Cultivars & 0.0 & 1.0 & 2.5 & 5.0 & $\mathrm{~A}$ & 1.0 & 2.5 & 5.0 & $\mathrm{~B}$ \\
\hline Chandler & $0.85 \pm 1.4$ & $0.93 \pm 0.5$ & $1.04 \pm 0.7$ & $1.06 \pm 1.0$ & 1.01 & $0.88 \pm 1.3$ & $0.99 \pm 1.1$ & $0.95 \pm 0.7$ & 0.94 \\
\hline Kaplan & $0.81 \pm 0.9$ & $0.87 \pm 1.2$ & $0.95 \pm 0.9$ & $0.98 \pm 1.1$ & 0.93 & $0.82 \pm 1.4$ & $0.90 \pm 1.0$ & $0.87 \pm 0.8$ & 0.86 \\
\hline$Y-1$ & $0.84 \pm 1.4$ & $0.91 \pm 1.3$ & $0.99 \pm 0.9$ & $1.02 \pm 0.9$ & 0.97 & $0.86 \pm 1.2$ & $0.94 \pm 0.9$ & $0.90 \pm 0.7$ & 0.90 \\
\hline overall mean & 0.83 & 0.90 & 0.99 & 1.02 & & 0.85 & 0.94 & 0.90 & \\
\hline
\end{tabular}

Evaluated 10 days-treatment etiolation after culture. Shoots per explant mean values with different letters between cultivars denote significant differences according to Tukey-Kramer multiple comparison test at $P<0.05$. Data are expressed as mean value \pm s.d.

A: Overall mean on Etiolation + TDZ effect at cultivar, B: Overall mean on Etiolation + IBA effect at cultivar.

The highest rooting $(66.74 \%)$ was obtained from 5.0 IBA dose in $Y-1$. IBA doses also significantly affected root number. The highest number of roots (3.97) was obtained from 1.0 IBA dose in the cultivar Chandler. IBA doses significantly affected root length. The highest root length $(3.28 \mathrm{~cm})$ was obtained from 2.5 IBA dose in Kaplan cultivar (Table III).

Etiolation or etiolation plus IBA and/or TDZ applications were found to be effective in the multiplication rates of cultivars. Following the etiolation treatment, the application of TDZ or IBA increased the multiplication and the rooting rates of cultivars. The highest multiplication rate (5.54) was obtained from 1.0 TDZ dose in Yalova-1 (Table IV). On the other hand, 2.5 IBA dose found to be the most effective dose in rooting. The highest rooting rate $(75.37 \%)$ was obtained from 2.5 IBA dose in Chandler (Table IV). These results were supported by Saadat and Hennerty [27].

The etiolation treatment alone did not affect the nodium length of the cultivars. However, the application of TDZ or IBA alone following etiolation significantly did not affect the nodium length of the cultivars (Table $\mathrm{V}$ ). In this study, 2.5 IBA dose was the most effective IBA dose in terms of the nodium length. The results have shown that etiolation + IBA 2.5 or etiolation + TDZ 2.5 combinations were found to be suitable for the micropropagation of walnut (Table V). These results were supported by Sánchez-Olate [28].

In vitro regeneration system was developed for apical shoot tips explant of walnut cultivars. Adventitious shoots were successfully produced on studied walnut cultivars. TDZ was more effective than IBA for shoot regeneration. The root induction was performed under dark conditions in the presence of IBA in the culture media. However, it needs further research in order to increase regeneration and survival rate. We described a method for micropropagation of walnut, by using various TDZ and IBA concentrations in in vitro conditions. If it successfully applied, this methodology could lead to the mass propagation of walnut cultivars within a relatively short period of time.

\section{References}

[1] G. McGranahan, C.A. Leslie, J.A. Driver, Hort. Sci. 23, 220 (1988)

[2] R. Kaur, K. Kumar, D.R. Sharma, S.D. Sharma, N. Sharma, Sci. Hortic. 109, 385 (2006).

[3] K. Kepenek, in: Proc. 24th Int. Horticultural Congress, Kyoto 1994, Abst. 0-7-1.

[4] C. Leslie, G. McGranahan, High-Tech and Micropropagation II, in series: Biotechnology in Agriculture and Forestry, Vol. 18, Eds. J.M. Widholm, J. Kumlehn, T. Nagata, Ch. I.7, Springer, Berlin 1992, p. 136.

[5] C. Jay-Allemand, D. Cornu, Ann. Sci. For. 43, 189 (1986).

[6] C. Jay-Allemand, P. Capelli, D. Cornu, Sci. Hort. 51, 335 (1992).

[7] R. Gruselle, N. Badia, P. Boxus, Acta Hort. 212, 511 (1987).

[8] R. Gruselle, P. Boxus, Acta Hort. 284, 45 (1990).

[9] J.M. Lopez, in: Proc. 6th Walnut Council Research Symp., Lafayette (USA), 2004, Gen. Tech. Rep. NC243. St. Paul, MN, U.S. Department of Agriculture, Forest Service, North Central Research Station, 2004, p. 146.

[10] S. Toosi, K. Dilmagani, J. Cell Biol. Genet. 1, 12 (2010).

[11] R. Rodriguez, M.A. Revilla, M.A. Albuerne, C. Pérez, in: Biotechnology in Agriculture and Forestry, Vol. 5, Trees 11, Ed. Y.P.S. Bajaj, Springer-Verlag, Berlin 1989, p. 99.

[12] J.E. Preece, J.W. Van Sambeek, C.A. Huetteman, G.R. Gaffney, in: The Continuing Quest for Quality. Proc. 4th Black Walnut Symp., Carbondale (USA), 1989, Ed. J.E. Phelps, p. 159.

[13] T.A. Thorpe, P.P. Kumar, in: Micropropagation of Woody Plants, Ed. M.R. Ahuja, Kluwer Academic, Netherlands 1993, p. 11.

[14] F.E. George, M.A. Hall, G.J. De Klerk, Plant Propagation by Tissue Culture. The Background, 3rd ed., Vol. 1, Springer, Dordrecht 2008.

[15] G. McGranahan, C.A. Leslie, in: Acta Hortic. 290, 907 (1991).

[16] J.M. Bonga, P.V. Aderkas, , In Vitro Culture of Trees, Kluwer Academic, Dordrecht 1992, p. 236. 
[17] M.J. Bosela, C.H. Michler, In Vitro Cell. Dev. Biol.Plant. 44, 316 (2008).

[18] M.J. Bosela, C.H. Michler, In Vitro Cell Dev. Biol. Plant. 44, 116 (2008).

[19] R. Rodriguez, C. López, C. Díaz-Sala, B. Berros, Acta Hort. 311, 141 (1993).

[20] J.A. Driver, A.H. Kuniyuki, Hort. Sci. 19, 507 (1984).

[21] G. Lloyd, B. McCown, Comb. Proc. Int. Plant. Prop. Soc. 30, 421 (1980).

[22] T. Murashige, F. Skoog, Physiol. Plant. 15, 473 (1962).

[23] M.A. Sanchez-Zamora, J. Cos-Terrer, D. FrutosTomas, R. Garcia-Lopez, Sci. Hort. 108, 317 (2006).

[24] M.A. Revilla, J. Majada, R. Rodriguez, Ann. Sci. For. (Paris) 46, 149 (1989).

[25] R. Rodriguez, Hort. Sci. 17, 592 (1989).

[26] F. Cossio, G. Minotta, Riv. Ortoflorofrutt. It. 67, 287 (1983) (in Italian).
[27] Y.A. Saadat, M.J. Hennerty, Sci. Hort. 95, 257 (2002).

[28] M. Sánchez-Olate, Ph.D. Thesis, Universidad de Oviedo, España 1996.

[29] K. Vahdati, C. Leslie, Z. Zamani, G. McGranahan, Hort. Sci. 39, 324 (2004).

[30] K. Kepenek, M.Sc. Thesis, S̈uleyman Demirel University, Faculty of Agriculture, Agricultural Biotechnology Department, Isparta, Turkey 2014 (in Turkish).

[31] Anonymous, SAS/STAT User's Guide, Release 6.03, Statistical Analysis System (SAS) Institute, Inc., Cary, NC 1988.

[32] L.D. Ríos, M. Sánchez-Olate, F. Avilés, M.E. Materan, M. Uribe, R. Hasbún, R. Rodríguez, in: Protocols for Micropropagation of Woody Trees and Fruits, Eds. S.M. Jain, H. Häggman, Springer, Dordrecht 2007, Ch. 35, p. 381. 